\title{
What particle verbs have to do with grammatical aspect in early child English ${ }^{*}$
}

\author{
Liane Jeschull \\ University of Leipzig \\ jeschull@rz.uni-leipzig.de
}

\begin{abstract}
The current study investigates the relation between aspect and particle verbs in the acquisition of English. Its purpose is to determine whether children associate telicity, as argued in previous studies, or rather perfectivity, which entails completion of a telic situation, with their early particle verb use. The study analyzes naturalistic data of four monolingual children between 1;6 and 3;8 from CHILDES acquiring English as their first language. On the one hand, it finds that children use both $-e d$ and irregular perfective morphology with simplex verbs before particle verbs. They further use imperfective before perfective morphology with particle verbs. These findings suggest that there is no correlation between telic particle verbs and perfective morphology, as would have been predicted on an account which claims that lexical aspect of predicates guides the acquisition of grammatical aspect (Olsen \& Weinberg 1999). On the other hand, the study finds that the children's particle verbs denote telic situations from early on, but not half of them were used to refer to situations that are also completed. This finding questions analyses which claim that, at an initial stage, children will only interpret predicates as telic if they refer to situations that are at the same time completed. Completion information is not necessary for children in order to use partick verbs correctly for telic situations, as would have been predicted on an extended account along the lines of Wagner (2001). As a conclusion, it is suggested that the divergent findings result from a difference in methodology. While restrictions of perfective and imperfective morphology to particular classes of lexical aspect pertain to the production of grammatical aspect morphology, perfective and imperfective viewpoints on situations pertain to the level of interpretation of telic and atelic situations.
\end{abstract}

\section{$1 \quad$ Aspectual systems}

The present paper re-emphasizes the need to distinguish between the two levels of aspect suggested in the literature in analyses of its acquisition. Lexical aspect, on the one hand, refers to what has traditionally been termed "Aktionsart", but also "inherent meaning of situations" (Comrie 1976), "aspectual class" (Dowty 1979), "situation aspect" (Smith 1991), "lexical contents" (Klein 1992, 1994) and "eventuality type" (Filip 1999). In the acquisition literature, it has often been called "lexical aspect" or "inherent lexical aspect" (Shirai \& Andersen 1995, Andersen \& Shirai 1996; Olsen \& Weinberg 1999; Li \& Shirai 2000 among others). Lexical aspect is determined by the inherent temporal properties of situations. It has been described in terms of Vendler's (1967) classification into "state", "activity", "accomplishment", "achievement" and other categories added to it or in terms of the inherent temporal features that such a classification is based on, like static vs. dynamic, punctual vs. durative, telic vs.

The present work is based on data from The ReVerb Database: verbal and sentential constructions in early child English, 2001, designed and compiled by M. Israel, P. Brooks and M. Tomasello, MPI for Evolutionary Anthropology, Leipzig, which I hereby gratefully acknowledge. 
atelic. Telicity is the property of situations of having an internal bound. Expressions denoting telic situations correspond to 2-state contents in Klein's $(1992,1994)$ terminology. 2-state contents consist of a source state and a target state. In the case of, for example, the situation of closing a door, the source state corresponds to the process of pushing or pulling the door that leads up to the target state of the door being closed. The contrast of the door not being closed and being closed is already contained in the lexical content of the expression close the door. As aspect is commonly assumed to be compositional in nature (cf. Verkuyl 1972, 1993; Comrie, 1976; Smith 1991; Klein 1992, 1994 among others), lexical aspect is not only expressed by the verb itself, but by the verb and its arguments.

Grammatical aspect, on the other hand, refers to what has been termed "aspect" per se (e.g. Comrie 1976; Klein 1992, 1994; Filip 1999), "aspectual form" (Dowty 1979) and "viewpoint aspect" (Smith 1991). In the acquisition literature, it has frequently been called "grammatical aspect" (Shirai \& Andersen 1995, Andersen \& Shirai 1996; Olsen \& Weinberg 1999; Li \& Shirai 2000; Wagner 2001 among others). Grammatical aspect specifies the perspective from which a situation is presented. Klein defines this level of aspect as "ways to relate the time of a situation to the topic time" (1994: 99). Situation time (TSit) here refers to the time for which a situation holds, while topic time (TT) refers to the time for which an assertion is made. TSit and TT can basically relate in the following ways: In the imperfective, "TSit is interpreted as fully including TT" (Klein 1994: 99), which is why the imperfective is perceived as viewing a situation from inside. In the perfective, "TSit is interpreted as partly including TT" (Klein 1994: 100), which is why the perfective gives the impression that it looks at a situation from outside. Here TSit can be fully included in TT. TT can overlap TSit and the pretime of TSit, i.e. the time before the time for which a given situation holds. It can also overlap TSit and the posttime of TSit, i.e. the time after the time for which a given situation holds. In the perfect and the prospective, "TSit is interpreted as excluding TT" (Klein 1994: 100). This means that, in the case of the perfect, TT is included in the posttime of TSit, while, in the case of the prospective, it is included in the pretime of TSit. These different viewpoints are variously marked by grammatical morphology and adverbials throughout the world's languages. Of the various ways in which lexical and grammatical aspect interact cross-linguistically (cf. Comrie 1976; Smith 1991; also Brinton 1988 for English), I will concentrate on the relationship between telicity and perfectivity in English in the following section.

\section{The English aspectual system}

In English, telicity as instantiation of lexical aspect can be expressed by simplex verbs with inherently telic semantics, like die or arrive. On the other hand, telicity in English has been shown to be expressed compositionally by the verb and its NP and PP arguments (cf. Verkuyl 1972, 1993; Dowty 1979; Tenny 1994; Brinton 1988 among others). Thus, transitive verbs with bounded NP complements, such as sing a song, sing the song, sing two songs, are telic, as are verbs of motion with goal PP arguments and directional adverbials, such as run to the store and run home. Finally, particle verbs, as in eat up the sausage and drink up the beer, are telic (cf. $\S 3$ below for discussion).

Grammatical aspect, is conveyed by the following morphology in English (Klein 1992: 113): Imperfective aspect, which expresses that TSit fully includes TT, is marked by the -ing form (Progressive Aspect), as in opening and writing. Perfective aspect, which in English can mean that TSit is fully included in TT or that TT overlaps TSit and the posttime of TSit (Klein 1994: 103), is marked by the simple form, as in opened and wrote. Perfect aspect, which expresses that TT is included in the posttime of TSit, is marked by the English Perfect form, as in opened and written. Prospective aspect, which means that TT is included in the pretime 
of TSit, is expressed by be going to, as in be going to open and be going to write. Note that an atelic predicate in the perfective, as in Petra ran, denotes that some arbitrary endpoint has been reached, since the topic time fully includes the time of the situation of Petra's running, in the present case, or overlaps the time of running and its posttime of not running. A telic predicate or 2-state content in the perfective, as in Martin closed the office door, is interpreted as having reached the inherent bound of the given situation and, therefore, seen as completed. As the bound is internal to telic predicates or 2-state contents, both the time of e.g. the action of pushing or pulling the door toward its closed position and the time of the door being closed are fully or partly included in the topic time. Here the time of the source state or process corresponds to TSit and the time of the target state of the door being closed corresponds to the posttime of the source state or process leading up to it. Hence, either the times of both source and target state are fully included in TT or TT overlaps source and target state.

Note further that the property of having an inherent goal or endpoint does not necessarily entail the attainment of that goal or endpoint. The property of having an inherent bound is an instance of lexical aspect and can be attributed to the internal temporal structure of telic predicates or 2-state contents, such as arrive, as they consist of a source state, here the approaching of the destination, and a target state, here the being at the destination. The attainment of the inherent bound is only entailed by perfective aspect, as an instance of grammatical aspect, since both the time of the source state and the time of the target state are fully included in TT or TT overlaps the time of the source state and the time of the target state, as in The train arrived. Imperfective aspect, on the other hand, does not entail the attainment of the target state in examples like The train was arriving, as TT is fully included in TSit and TSit again corresponds to the source state or process of approaching the destination. Thus, the target state of finally being at the destination may have been reached or it may not have been because something unexpected happened shortly before the train's anticipated arrival, say an axle broke. The Imperfective Paradox, as the phenomenon has been called (cf. Dowty 1979: 133), can also be observed with particle verbs, which shows that they are telic in nature.

\section{$3 \quad$ Particle verbs and aspect}

A semantic problem in the treatment of particle verbs is that they can carry spatial, idiomatic and aspectual meaning. The latter has been attributed to lexical aspect by some researchers and to grammatical aspect by others (see Brinton 1985, 1988 for an overview). Brinton (1985) argues in detail that particle verbs express telicity, not perfectivity. As they determine the lexical aspect of the events they refer to, they are nevertheless compatible with grammatical aspect morphology: the imperfective (cf. 1a), the perfective (cf. 1b) and the perfect (cf. 1c).

(1) a. She was eating up the ice-cream.

b. She ate up the ice-cream.

c. She has eaten up the ice-cream.

Moreover, Brinton argues that it is the particle itself that "may add the concept of a goal or an endpoint to durative situations which otherwise have no necessary terminus" (1985: 160). For example, the event denoted by the simplex verb eat does not have any internal boundary, while eat up denotes an event that includes the inherent goal or endpoint of total consumption of the thing to be eaten, e.g. the ice-cream. 
Drawing on Dowty (1979), Brinton (1985: 162ff.) cites a series of tests to support the telicity analysis. First, particle verbs can appear with the construction take X time to (cf. 2) and can be modified by time adverbials with in (cf. 3).

(2) It took her months to write up the paper.

(3) She wrote up the paper in a night.

Second, particle verbs used with the matrix verb finish entail that the inherent bound has been reached (cf. 4). When used with stop, however, they do not (cf. 5). This pattern emerges because the particle verbs are telic in the first place.

(4) She finished carrying out the experiment. = She carried out the experiment.

(5) She stopped carrying out the experiment (before it was finished).

As a third indication of the telicity involved, particle verbs modified by the adverb almost have ambiguous interpretations (cf. 6). On the one hand, they may entail that the event took place, but did not reach its inherent goal. On the other hand, they may entail that the event in question was about to start, but did not take place at all.

(6) She almost carried out the experiment.

Taken together, these tests provide evidence that, beside the lexical content itself, an inherent temporal property of lexical contents of particle verbs, like drink up, is that they have an internal bound. On an account along the lines of Klein $(1992,1994)$, the internal bound stems from the contrast between the source state of drinking and the target state of the glass or bottle being empty, in this case.

Finally, telicity interacts with grammatical aspect, when particle verbs occur with imperfective and perfective morphology. In the imperfective in (7a), TT is fully included in the source state or process of doing the experiment. Therefore, the sentence does not entail completion of the experiment.

(7) a. She was carrying out the experiment (but fell seriously ill before she was able to finish it).

b. She carried out the experiment.

The perfective in (7b), however, denotes the attainment of the goal of the experiment being finished, as TT fully or partly overlaps both source and target state.

\section{$4 \quad$ Acquisition of tense and aspect}

Researchers in first language acquisition have long known and often described that children across a wide variety of languages initially restrict their verbal morphology according to the aspectual construal of the events denoted by the predicates. Among the first to notice such a restriction were Brown (1973) for naturalistic English data, Bronckart \& Sinclair (1973) for elicited French data, Antinucci \& Miller (1976) for naturalistic Italian and English data and Bloom et al. (1980) for naturalistic English data. Thus, children acquiring English as their first language initially limit their use of past tense and progressive -ing to the description of particular events in a very regular fashion. Despite some divergent analyses of the details, the common finding is that the morpheme $-e d$ and irregular past morphology are initially 
restricted to events having an inherent bound and/or a result, while the progressive morpheme -ing is initially restricted to durative events.

Shirai \& Andersen (1995) and Andersen \& Shirai (1996) call this phenomenon the "Aspect Hypothesis" or "Primacy of Aspect" (POA) hypothesis and define it as the "phenomenon of limiting a tense-aspect marker to a restricted class of verbs, according to the inherent aspect of the verb" (1996: 529). This definition pertains to a descriptive level of analysis of children's linguistic performance in spontaneous and elicited production contexts more than it is meant to explain the reported findings. The authors find that English past morphology is restricted to predicates denoting events that are telic, punctual and resultative at the emergent stage. They further claim that progressive -ing is initially restricted to activity verbs and "iterative achievement verbs", that is, verbs that denote durative events. The initial restrictions are later relaxed to include other situation types. On the basis of these findings, the authors argue that it is inherent lexical aspect that guides the initial restriction of verbal morphology. However, resultativity is itself entailed by a perfective viewpoint on a telic event, rather than by lexical aspect per se. Moreover, their class of "iterative achievement verbs" does not necessarily constitute a natural class of lexical aspect. Instead, iterativity here appears to be the result of an imperfective viewpoint on punctual events, resulting in a series of repeated actions, which in turn is marked by -ing itself. For example, jumping was classified as "iterative achievement verb" (Shirai \& Andersen 1995: 754f.). Yet the verb jump itself is punctual and denotes a singular event; it only becomes iterative by virtue of the progressive morpheme -ing.

The author's explanation of the reported findings is based on a prototype account of acquisition, according to which the prototype of a particular category is acquired first and less prototypical members emerge only later. Thus, they argue that achievements, which are telic and punctual, constitute the prototype of the category past tense, while activities, which are durative and atelic, constitute the prototype of the category progressive. The past and progressive inflections, in this sense, attach to the verbs whose meaning they are most "congruent" with (Andersen \& Shirai 1996: 554). The explanation in terms of prototypes and "congruence" between lexical aspect of predicates and grammatical aspect and tense morphology still leaves open an answer to the question in what direction the initial restriction works. Shirai \& Andersen (1995: 759) hypothesize that children might initially encode either lexical or grammatical aspect. Yet implications differ considerably for the two. If children choose to attach inflectional morphology only to a particular set of predicates according to their lexical aspect, tense and grammatical aspect will initially be underextended. If they encode the lexical aspect of predicates in their use of inflectional morphology, their grammatical aspect marking will be redundant with lexical aspect. Thus, the question remains: what kind of information do children use primarily when acquiring the aspectual systems of their native languages - lexical or grammatical aspect?

Olsen \& Weinberg (1999) suggest that, at an early stage of development, children use lexical aspect information to acquire grammatical aspect. Their classification of lexical aspect is based on the features "telic", "dynamic" and "durative", which can be "+" or "0" (unmarked). In their analysis of the distribution of verbal morphology in English, they find that -ed and its irregular counterpart are initially restricted to [+telic] predicates, while -ing is initially restricted to [+dynamic] and [+durative] predicates. On the other hand, predicates that are [+telic] occur with both $-e d$ and -ing, since they are at the same time [+dynamic]. Olsen \& Weinberg suggest an explanation for their findings in terms of universal and innate principles that govern the relationship between lexical aspect and grammatical aspect in the process of their acquisition as well as in cross-linguistic variation. On this account, the initial stage for children is the most restrictive version and, hence, forms a subset of the aspectual system in languages that are less restrictive, like English. In subsequent stages of development, the 
subset is relaxed to include predicates unmarked for the respective features upon encounter of positive evidence. As a result, Olsen \& Weinberg clearly propose that it is lexical aspect that guides the acquisition of grammatical aspect.

Wagner (2001) studied the validity of what she calls the "Aspect First hypothesis" for children's comprehension of verbal morphology. She found that children correctly recognized verbal morphology as marked by a form of the copula be plus progressive -ing if temporal ordering of events coincided with grammatical aspect. Thus, children correctly referred to past-time events when the past tense was used, to present-time events when the present tense was used and to future-time events when the future tense was used. At the same time, the past-time events were also completed, while the present-time events were incomplete. Wagner concludes that completion entailments may have influenced their performance, but the children were able to differentiate all three tenses, even the group of two-year olds, the youngest age group tested. These findings contradict a hypothesis as general as "Aspect First". On the other hand, Wagner studied children's comprehension of verbal morphology (again as marked by a form of the copula be plus progressive -ing) in a setting where temporal ordering of events did not coincide with grammatical aspect in the form of completion information. She found that the group of two-year old children were only able to distinguish between past and present tense, when temporal ordering of events coincided with grammatical aspect: past tense with completed events and present tense with incomplete events. The three-year olds and four-year olds tested were able to distinguish between past and present tense both when events were completed and when they were incomplete, although all groups of children performed worse when past-time events were incomplete. These results apparently support the "Aspect First Hypothesis". However, what the results have shown and Wagner suggests is a more specific version of the primacy-of-aspect hypothesis, namely primacy of grammatical aspect.

\section{$5 \quad$ Acquisition of aspect and particle verbs}

The present study addresses the issue of primacy of lexical or grammatical aspect with regard to the acquisition of particle verbs in English. Children's exceptional treatment of particle verbs has been shown to stand out among the aspectual systems of several Germanic languages. In particular, it is argued to relate to the acquisition of telicity. Van Hout (1998 a, b, 2001) tested three-, four- and five-year old children acquiring English and Dutch as their first language on their aspectual interpretation of the particle verbs eat up and drink up and intransitive and transitive structures involving the simplex verbs eat and drink. She found that, from the beginning, children distinguished sentences with particle verbs from all other structures, including intransitive eat and drink, transitive verbs with bare NP complements, such as eat cheese and drink coke, and transitive verbs with bounded NP complements, such as eat his/her cheese and drink his/her coke. Children attributed telic readings to particle verbs more often than to all other structures, regardless whether these are interpreted as telic or not by adult speakers of the target language.

Schulz \& Penner (2002) tested children between the ages of $4 ; 1$ and $6 ; 4$ acquiring German as their first language on their understanding of the particle verbs aufessen ('eat up') and austrinken ('drink up'), in a parallel fashion to van Hout's study. They found that both children and adults accepted the telic particle verbs to refer to completed situations, but rejected them in case of incomplete situations. Both groups also accepted the atelic intransitive simplex verbs essen ('eat') and trinken ('drink') to refer to both completed and incomplete situations. Further, both groups behaved alike in accepting telic structures involving a simplex verb with a quantized NP complement, like den Apfel essen ('eat the 
apple'), to refer to completed situations, while accepting these structures for half of the incomplete situations and rejecting them for the other half. Thus, children performed in an adult-like manner on all verb types tested. Both children and adults treated the verbs with quantized NP complements ambiguously, while they unambiguously allowed particle verbs only to refer to completed situations. Schulz \& Penner conclude that particle verbs are strong markers of telicity and as such fully mastered by the children in this study.

Schulz et al. (2001, 2002) and Penner et al. (2003) also tested normally-developing children between 2;00 and 4;10 acquiring German as well as language-impaired children between 3;10 and 8;07 and an adult control group on their understand ing of the telicity entailment of the particle verb aufmachen ('to open'). They found that all groups accepted the particle verb to refer to situations where the end-state of a container opened is reached. The normally developing children also rejected it for the majority of situations where the endstate of aufmachen is not reached, as did the adult native speakers. The authors conclude that normally developing children have acquired the end-state-orientation of the particle verb aufmachen as early as at the age of two. In sum, particle verbs stand out as a robust phenomenon among all other telic structures for adults as well as for normally developing children as young as two years of age.

The authors of all of the above studies argue that children, by their performance in the experiments, show knowledge of telicity as associated with particle verbs, i.e. they know that particle verbs have an inherent goal or endpoint. Yet the situations presented to them in all of the studies differed as to whether the situations were completed or not. Thus, telicity of the predicates in question coincided with a perfective viewpoint, which entails the completion of the inherent goal or endpoint of the situations presented visually. For example, the apple was eaten up or the container was opened. Moreover, the trigger sentences used either perfective or perfect aspect as expressed by the Simple Past in English, the Present Perfect in Dutch and the Perfect in German. For example, van Hout asked her subjects:

(8) Heeft de rode/witte muis zijn kaasje opgegeten? (van Hout 1998a: 402)

Did the red/white mouse eat up his cheese?

Schulz, Penner and colleagues asked:

(9) Hat das Mädchen ausgetrunken?

(Schulz \& Penner 2002: 243)

has the girl UP.drunk-part

'Did the girl drink up?'

and

$\begin{array}{lll}\text { (10) Hat } & \text { siese } & \text { aufgemacht? } \\ \text { has } & \text { she-her.CL } & \text { AUF-made.PART }\end{array}$

(Schulz et al. 2001: 412)

'Did she open it?'

These facts give the impression that children in their use of particle verbs also encode perfectivity rather than telicity alone. If this is so, it will support Wagner's (2001) hypothesis that grammatical aspect information has primacy in the acquisition of tense-aspect systems.

The obvious questions to be addressed now are: What kind of aspectual information do children map onto their early particle verbs: telicity or perfectivity? What do children initially encode: lexical aspect or grammatical aspect? In answer to these questions, two logical possibilities emerge. (I) If they initially use lexical aspect information, children will map telicity onto their particle verbs from early on. They will initially restrict their perfective morphology to telic predicates, where perfectivity entails completion, i.e. attainment of the 
inherent bound of the situation. They will initially not use perfective morphology with atelic predicates, where perfectivity denotes termination, i.e. attainment of an arbitrary endpoint. This reasoning is in line with Olsen \& Weinberg (1999). Predictions for the acquisition of particle verbs that follow from this possibility and Olsen \& Weinberg's hypothesis are: (Ia) Perfective morphology will be used with particle verbs before simplex verbs, as particle verbs are telic. (Ib) Particle verbs will be used with perfective morphology before imperfective morphology. (II) If they initially use grammatical aspect information, children will map perfectivity onto their early particle verbs. They will only recognize predicates as telic when the situations they refer to are also completed, i.e. the inherent bound is reached. Children will initially interpret particle verbs as encoding completion rather than telicity itself. This is an extended version of Wagner (2001). Predictions that follow from it are: (IIa) Perfective morphology will be used with simplex verbs before particle verbs. (IIb) Particle verbs will not be used with perfective morphology before imperfective morphology, if they entail completion themselves.

\section{The Study}

The analysis is based on longitudinal data of four monolingual children from CHILDES acquiring English as their first language (cf. table 1), which were drawn from the ReVerb Database, as was the coding of the data (cf. Israel 2001).

Table 1. Data comprising the study

\begin{tabular}{llll}
\hline Child & Age & MLU & Corpus \\
\hline Eve & $1 ; 6-2 ; 3$ & $1.5-3.4$ & Brown (1973) \\
Naomi & $1 ; 6-3 ; 8$ & $1.2-3.9$ & Sachs (1983) \\
Peter & $1 ; 9-2 ; 7$ & $1.2-3.6$ & Bloom (1975) \\
Nina & $1 ; 11-2 ; 10$ & $1.8-3.4$ & Suppes (1973) \\
\hline
\end{tabular}

The four children were chosen to ensure that the data covered the onset of inflectional morphology and data were available from before age 2;0 (MLU stage I). The organization of the data into developmental stages follows Brown (1973: 56), cf. table 2:

Table 2. Stages by MLU

\begin{tabular}{lc}
\hline Stage & MLU \\
\hline I & $<2.0$ \\
II & $2.0<2.5$ \\
III & $2.5<3.0$ \\
IV & $3.0<3.5$ \\
\hline
\end{tabular}

Following Brown (1973: 58), stage I includes all utterances between MLU 1.0 and 2.0. Contrary to Brown, however, the MLUs of all stages differ by 0.5 in order to ensure that the same amount of data were available for analysis across developmental stages for all children and to maintain comparability of the data from the four children in terms of MLU at all stages. The MLUs of the children were calculated by use of the CLAN tool mlu (MacWhinney 1995). The analysis includes all non-imitative utterances with a particle verb and, for the purpose of comparison, also all utterances with a simplex verb in a finite context. 


\section{$7 \quad$ Results}

Figure 1 shows the children's use of inflectional morphology with particle verbs, and figure 2 with simplex verbs.

Figure 1. Morphology with particle verbs

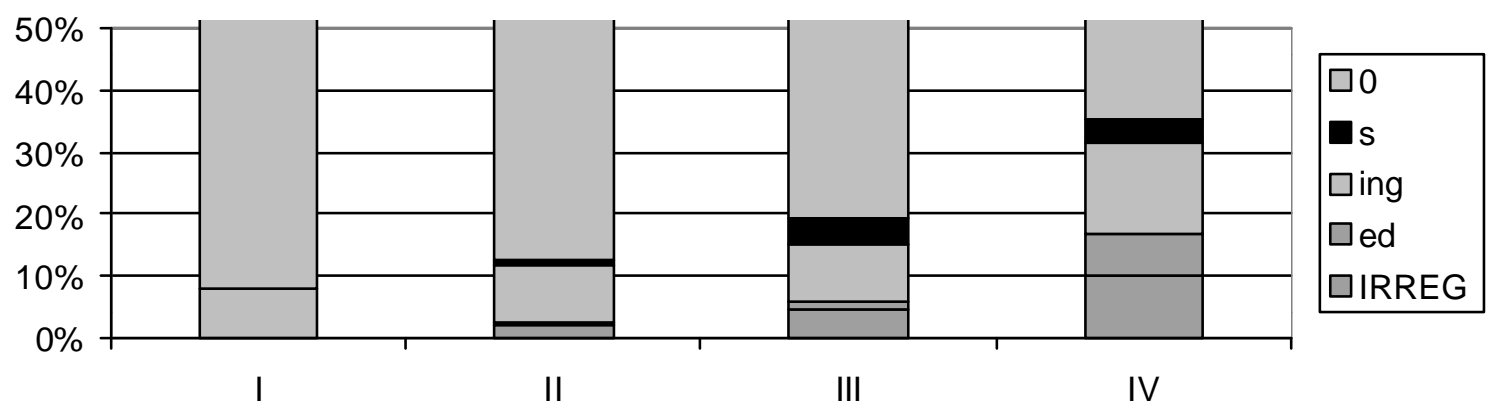

Figure 2. Morphology with simplex verbs

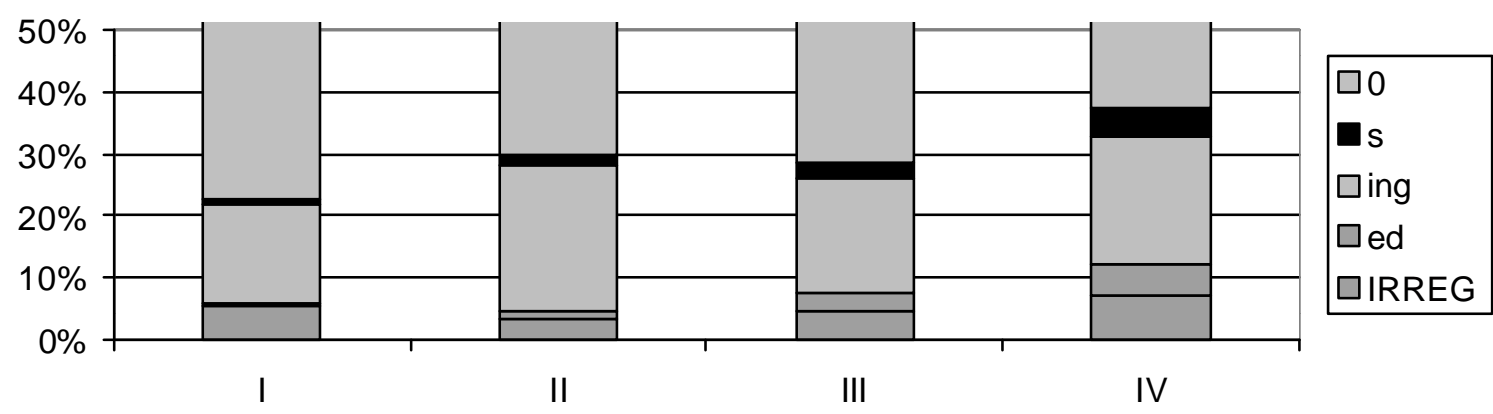

The figures reveal that, first, throughout development up to stage III, particle verbs are inflected less frequently than simplex verbs. Inflection of particle verbs only catches up at stage IV, the last stage investigated here. Second, all children produce perfective morphology with simplex verbs before particle verbs. More precisely, perfective aspect emerges with simplex verbs as early as at stage I, but with particle verbs only at stage II. Third, both the morpheme -ed and irregular perfective morphology emerge at the same time: at stage I with simplex verbs and at stage II with particle verbs. Irregular perfective morphology is not produced earlier than $-e d$, neither on particle verbs nor on simplex verbs. Fourth, imperfective -ing is produced as early as at stage I both with particle verbs and with simplex verbs. Thus, imperfective aspect emerges earlier than perfective aspect with particle verbs, whereas both emerge at the same stage with simplex verbs.

In order to see whether there is variation between the children in their use of aspectual morphology with particle verbs, figures 3 and 4 show the proportion of particle verbs used with perfective and imperfective inflection respectively. ${ }^{1}$

\footnotetext{
${ }^{1}$ For Nina, data start only at stage II.
} 
Figure 3. Perfective morphology with particle verbs

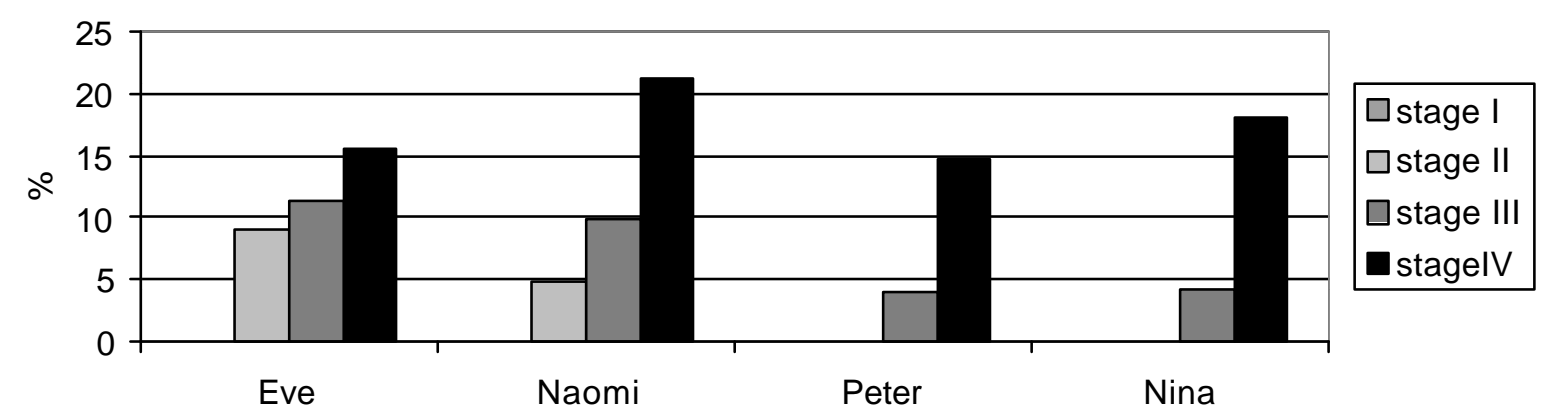

Figure 4. Imperfective morphology with particle verbs

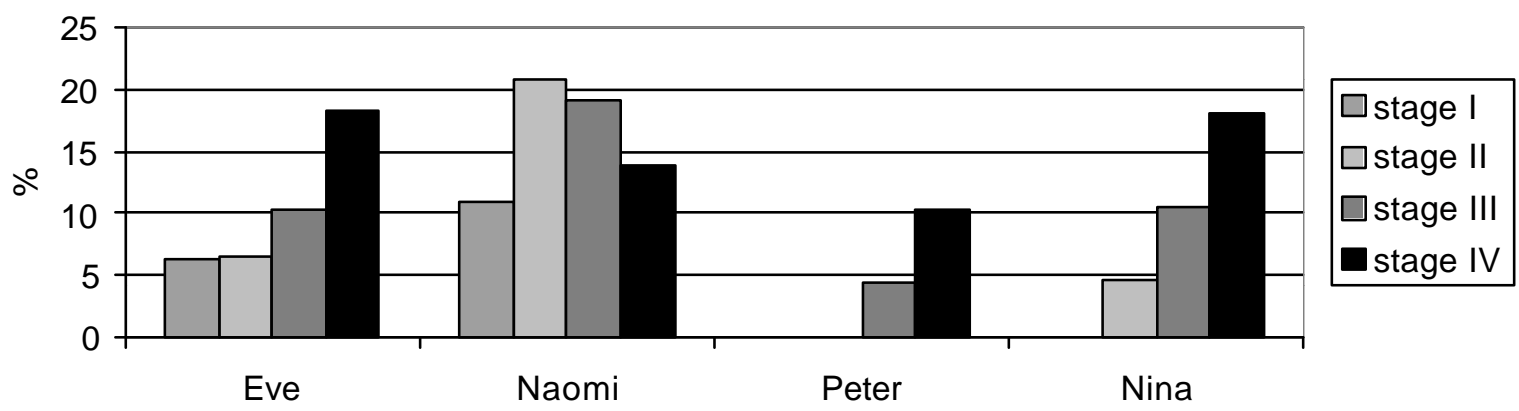

The individual results mirror the overall pattern observed in figure 1. All children use imperfective morphology before they use perfective morphology with particle verbs, except for Peter, who starts to use both at the same stage. Eve and Naomi first produce particle verbs with imperfective morphology at stage I and with perfective morphology at stage II, while Nina's first particle verbs with imperfective morphology can be found at stage II, the first stage where data from her are coherently available, and with perfective morphology at stage III. For all children, the proportion of both perfective and imperfective morphology with particle verbs increases from stage to stage. Only Naomi exhibits a somewhat different pattern in her use of imperfective -ing. Hence, there is no initial restriction to perfective morphology. Instead particle verbs are used with both perfective and imperfective inflection from stage II onwards. The finding that telic predicates, like particle verbs, are not initially restricted to perfective morphology, is in line with Olsen \& Weinberg's findings.

In order to investigate whether children use their earliest particle verbs to refer to telic or rather completed situations, stage I was analyzed in further detail, cf. table 3.

Table 3. Particle verbs at stage I

\begin{tabular}{|c|c|c|c|c|c|}
\hline Child & $\begin{array}{l}\text { Properties } \\
\text { un inflectec }\end{array}$ & $\begin{array}{l}\text { ations denoted by } \\
\text { le verbs }\end{array}$ & $\begin{array}{l}\text { Morphological } \\
\text { particle verbs }\end{array}$ & marking & with \\
\hline & telic & completed & $\varnothing$ & -ing & \\
\hline Eve & $14(100 \%)$ & $3(21 \%)$ & $14(93 \%)$ & $1(7 \%)$ & \\
\hline Naomi & $79(94 \%)$ & $37(47 \%)$ & $84(87 \%)$ & $12(13 \%)$ & \\
\hline Peter & $31(100 \%)$ & $6(19 \%)$ & $31(100 \%)$ & 0 & \\
\hline
\end{tabular}

Table 3 shows that all particle verbs are indeed telic, except for four tokens of idiomatic watch out used by Naomi (15) and an instance of need on, the meaning of which is not quite clear, cf. (11). 
(11) need sugar on.

(Naomi (14))

It further reveals that $19 \%$ to $47 \%$ of the uninflected telic particle verbs at this stage were used to denote completion of an event. Examples are given in (12) and (13):

(12) MOT: now everything is on the floor .

MOT: all your toys are on the floor .

MOT: no \# Nomi \# you can't walk with all the toys on the floor .

MOT: you've got so many toys on the floor .

CHI: fall down .

(Naomi (04))

(13) CHI: I slide down .

FAT: $\quad$ Nomi \# you slid down the wrong side .

(Naomi (20))

As was shown graphically in figure 1, between $7 \%$ and $13 \%$ of all particle verb tokens are inflected and occur with -ing at this stage. None of these are overgeneralized to completed situations. Examples are given in (14) and (15).

(14) CHI: lying down .

MOT: oh \# you're lying down .

(Eve (04))

(15) CHI: sun going down .

FAT: no \# this sun has just come up .

FAT: it won't go down until the end of the day .

(Naomi (15))

\section{Discussion}

The results of the present study confirm predictions (IIa) and (IIb). Perfective morphology is indeed used with simplex verbs before particle verbs. Particle verbs are used with imperfective -ing before perfective morphology. Uninflected particle verbs may be used to refer to completed situations, but -ing is not overgeneralized to completed situations. This pattern looks as though children treat particle verbs as entailing telicity and completion and, therefore, delay their use of perfective markers with particle verbs. From a purely morphological point of view on grammatical aspect, it seems that children may map perfectivity onto the structure of particle verbs themselves. On this account, children may associate grammatical aspect with their uninflected telic particle verbs at stage I, which would confirm hypothesis (II). However, completion is not a necessary condition for children to use particle verbs for telic situiations. An alternative explanation for the divergence between simplex verbs and particle verbs with regard to verbal inflection here could be performancebased. Thus, if a child has an MLU of 2.0, she has two "slots" available for uttering either a simplex verb $+-e d$ or a verb + particle, provided she analyzes verb and particle into two constituents. However, this account does not explain why irregular perfective morphology is not produced with particle verbs prior to regular $-e d$, as an irregularly inflected particle verb would not occupy more than two slots. Nor does it explain why children do produce -ing with particle verbs as early as at stage $\mathrm{I}$.

On the other hand, the findings of the present study also support assumptions underlying predictions (Ia) and (Ib), even though they do not confirm the predictions with regard to 
aspectual morphology. From the point of view of grammatical aspect interpretations, the data of stage I support hypothesis (I), which claims that children initially use lexical aspect information. Thus for children, particle verbs entail telicity and are, therefore, associated with lexical aspect interpretations from early on. While virtually all of their particle verbs were found to be telic, not even half of the uninflected tokens were also used for completed situations at stage I. From this perspective, lexical aspect has primacy. The lack of correlation between telicity and perfective markers, which has been found in previous studies, has a straightforward explanation on a subset-principle account. Olsen \& Weinberg (1999) have argued that acquisition of grammatical aspect via lexical aspect initially constrains perfective markers to telic situations, but does not in turn restrict telic predicates to perfective morphology. They found that only between $67 \%$ and $97 \%$ of telic predicates were used with ed across stages I through IV in their data. As telic predicates, such as particle verbs, are also dynamic and can be durative as well, the subset principle equally well explains why they also appear with -ing from early on. The same relation holds for the particle verb data investigated here: telic particle verbs are not confined to perfective inflections even at an early stage of development.

What is at stake here is a dichotomy in the type of data analyzed in the present study as well as between previous analyses of the acquisition of aspect. Analyses along the lines of Olsen \& Weinberg (1999), which claim the primacy of lexical aspect, pertain to the distribution of grammatical aspect morphology. The analysis advanced by Wagner (2001), which claims the primacy of grammatical aspect, pertains to children's interpretation of aspectual and temporal morphology and, by extension, of particle verbs. The present study investigated both the distribution of aspectual morphology with and children's aspectual interpretations of particle verbs. Thus, it also tried to track down children's understanding of particle verbs from the way they used them in spontaneous speech, but such an analysis is seriously limited. Therefore, controlled comprehension experiments are needed to shed more light on the question of what kind of aspectual information children map onto their early particle verbs, be it telicity or perfectivity or both. In the end, the dichotomy in findings and analyses might boil down to a difference between production and comprehension in the acquisition of aspect.

\section{References}

Andersen, R. W. \& Y. Shirai (1996). The primacy of aspect in first and second language acquisition: The pidgincreole connection. In W. C. Ritchie \& T. K. Bhatia (eds.): Handbook of second language acquisition. New York et al.: Academic Press.

Antinucci, F. \& R. Miller (1976). How children talk about what happened. Journal of child language 3, 167-189.

Bloom, L. (1975). Language development. In F. Horowitz (ed.): Review of child development research, Vol. 4. Chicago: University of Chicago Press.

Bloom, L. et al. (1980). Semantics of verbs and the development of verb inflection in child language. Language 56/2, 386-412.

Brinton, L. J. (1985). Verb particles in English: Aspect or aktionsart? Studia Linguistica 39/2, 157-168.

- (1988). The development of English aspectual systems. Cambridge et al.: CUP.

Bronckart, J. P. \& H. Sinclair (1973). Time, tense and aspect. Cognition 2/1, 107-130.

Brown, R. (1973). A first language: The early stages. Cambridge, MA: Harvard UP.

Comrie, B. (1976). Aspect. Cambridge: CUP.

Dowty, D. R. (1979). Word meaning and Montague grammar: The semantics of verbs and times in generative semantics and in Montague's PTQ. Dordrecht et al.: Reidel.

Filip, H. (1999). Aspect, eventuality types and nominal reference. New York \& London: Garland.

Israel, M. (2001). The ReVerb code book. Ms. MPI for Evolutionary Anthropology, Leipzig. 
Klein, W. (1992). Tempus, Aspekt und Zeitadverbien. Kognitionswissenschaft 2, 107-118.

- (1994). Time in language. London \& New York: Routledge.

Li \& Shirai (2000). The acquisition of lexical and grammatical aspect. Berlin \& New York: Mouton de Gruyter.

MacWhinney, B. (1995). The CHILDES project: Tools for analyzing talk. $2^{\text {nd }}$ ed. Hillsdale, NJ: Erlbaum.

Olsen, M. \& A. Weinberg (1999). Innateness and the acquisition of grammatical aspect via lexical aspect. In A. Greenhill et al. (eds.): BUCLD 23 Proceedings, 529-540. Somerville, MA: Cascadilla.

Penner, Z. et al. (2003). Learning the meaning of verbs: What distinguishes language impaired from normally developing children? Linguistics 41/2, 289-319.

Sachs, J. (1983). Talking about the there and then: The emergence of displaced reference in parent-child discourse. In K. E. Nelson (ed.): Children's language, Vol. 4. Hillsdale, NJ: Erlbaum.

Schulz, P. et al. (2001). The early acquisition of verb meaning in German by normally developing and language impaired children. Brain and language 77, 407-418.

- (2002). Comprehension of resultative verbs in normally developing and language impaired German children. In F. Windsor et al. (eds.): Investigations in clinical phonetics and linguistics, 115-129. Mahwah, NJ: Erlbaum.

Schulz, P. \& Z. Penner (2002). How you can eat the apple and have it too: Evidence from the acquisition of telicity in German. In J. Costa \& M. J. Freitas (eds.): Proceedings of the GALA 2001 conference on language acquisition, 239-246.

Shirai, Y. \& R. W. Andersen (1995). The acquisition of tense-aspect morphology: A prototype account. Language 71/4, $743-762$.

Smith, C. S. (1991). The parameter of aspect. Dordrecht et al.: Kluwer.

Suppes, P. (1973). The semantics of children's language. American psychologist 88, 103-114.

Tenny, C. L. (1994). Aspectual roles and the syntax-semantics interface. Dordrecht et al.: Kluwer.

van Hout, A. (1998a). The role of direct objects and particles in learning telicity in Dutch and English. In A. Greenhill et al. (eds.): BUCLD 22 Proceedings, 397-408. Somerville, MA: Cascadilla.

- (1998b). On learning the role of direct objects for telicity in Dutch and English. In B. Hollebrandse (ed.): New perspectives on language acquisition, 87-104. UMass Occasional Papers 22. Amherst: GLSA.

- (2001). Acquiring telicity cross-linguistically: On the acquistion of telicity entailments associated with transitivity. To appear in: M. Bowerman \& P. Brown (eds.): Crosslinguistic perspectives on argument structure: Implications for learnability. Hillsdale,NJ: Erlbaum.

Vendler, Z. (1967). Linguistics in Philosophy. Ithaca: Cornell UP.

Verkuyl, H. J. (1972). On the compositional nature of the aspects. Dordrecht: Reidel.

- (1993). A theory of aspectuality. Cambridge: CUP.

Wagner, L. (2001). Aspectual influences on early tense comprehension. Journal of Child Language 28, 661-681. 